\title{
Valuation of switchable tariff for wind energy
}

\author{
Wang Yu ${ }^{a}$, Gerald B. Shebléa,*, Joao A. Peças Lopes ${ }^{\mathrm{b}}$, Manuel António Matos ${ }^{\mathrm{b}}$ \\ ${ }^{a}$ Department of Electrical Engineering, Iowa State University, IA, USA \\ ${ }^{\mathrm{b}}$ Department of Electrical and Computer Engineering, Universidade do Porto, Porto, Portugal
}

Received 12 July 2005; accepted 2 September 2005

Available online 15 December 2005

\begin{abstract}
The current fixed tariff remuneration for wind energy is not compatible with the deregulation of the electric power industry. The time-varying and location-dependent value of renewable energy is not acknowledged. The newly announced switchable tariff for wind energy in the Spanish electricity market provides a promising solution to compensating renewable energy within the deregulated electric power industry. The new switchable tariff provides wind generators more flexibility in operating wind generation assets. Such flexibilities provide option value in coordinating the seasonality of wind energy, demand on electric power and electricity prices movement. This paper models and valuates the flexibility on switching tariff as real compound options for wind generators. Numerical examples valuate wind generation assets under fixed tariff, spot market price taking, and yearly and monthly switchable tariffs. The optimal switching strategies are identified. The impacts of the switchable tariff on sitting criteria and values of wind generation assets are investigated. An improvement on the yearly switchable tariff is suggested to further reduce the operation risk of wind generators and fully explore the efficiency provided by competitive electricity markets.
\end{abstract}

(C) 2005 Elsevier B.V. All rights reserved.

Keywords: Real option; Renewable energy; Spanish electricity markets; Switchable tariff; Valuation; Wind generation

\section{Introduction}

The present trend to encourage the installation of wind generation is based on the benefits of renewable resources that are of minimum environmental impact. These assets are being installed in very large numbers around the world as fossil resources have become scarcer and continue to cause problems environmentally, politically and socially. The European Union aims to supply $22 \%$ of electricity demand from renewable energy sources by 2010 . Wind power has been growing at an annual rate of 55\% in Europe [1]. American Wind Energy Association (AWEA) estimates that, with steady, supportive policies including proactive regional transmission planning, wind power can provide at least $6 \%$ of US electricity by 2020 [2]. Another current trend to deregulate the electric power industry is based on the benefit of efficiency from competition. Regional electricity markets have been implemented and operating in Australia, Europe and North America. The pursue of efficiency and environment

\footnotetext{
* Corresponding author. Present address: Room 1115 Coover Hall, Ames, IA 50011, USA. Tel.: +1 515294 3046; fax: +1 5152944263 .

E-mail address: gsheble@iastate.edu (G.B. Sheblé).
}

should be coordinated to provide low cost and clean electric energy.

Wind generators were and still are compensated at fixed regulated tariffs within some re-regulated electricity markets. The Public Utility Regulation Policies Act (PURPA) in US qualifies wind energy as Small Power Producer Qualifying Facility (SPP QF). The SPP QF enables wind generators to sell their output at the regulated "avoided cost" of traditional generating technologies. A wind generator in Spanish electricity market was entitled under Royal Decree 2818 of December 23, 1998, to receive a fixed regulated price on its output.

The regulated fixed tariff does not incorporate the timevarying and location-dependent value of electricity, thus incompatible with the re-structuring of the electric power industry. The incorporation of time-varying and location-dependent value of electricity will change both the values and sitting criteria of wind generation assets. A wind generator's capability to produce electric power to meet the peak electric power demand is expected to be worthy more. A more efficient utilization of wind resources is expected within the electricity markets.

California Independent System Operator (CAISO) proposed a special service to encourage wind generation to leave the umbrella of PURPA to join the California electricity market [3]. 
The approach was to award wind generators with monthly average price if wind generators agree to put their generation assets under the control of CAISO. The Royal Decree 841 of August 2, 2002, in Spain entitled a wind generator to participate the Spanish electricity market and receive a variable price calculated from the average price of the market-pool, plus a bonus. Such market rules provide incentives to renewable generator to participate in the deregulated electricity market. Twenty-one producers under special regime entered the Spanish electricity market during September 2002-March 2003 with a total capacity of $1249 \mathrm{MW}$. The generators either present bid directly into the Spanish electricity market or using a production aggregator.

The Spanish electric power authorities proposed switchable tariff to further address the problem of encouraging more renewable energy producer to participate the Spanish electricity, and of compensating renewable energy within deregulated electricity markets. Real Decreto 436/2004, de 12 de março 2004 [4] defines that a wind generator can choose between:

- Fixed tariffs defined for all hours of the day, calculated as $90 \%$ of the average tariff, that is $€ 6.48648 \mathrm{c} \mathrm{kWh}^{-1}$ for 2004 (the average tariff for 2004 equals to $€ 7.2072 \mathrm{c} \mathrm{kWh}^{-1}$ ).

- Participate in the market where it will be remunerated by the market price plus a prize ( $40 \%$ of the market price) and plus an incentive ( $10 \%$ of the market price), that is $150 \%$ of the market price.

A wind generator, when selecting one remuneration scheme, has to stay for a minimum time of one year under this remuneration option. It should request any change with a month in advance. This switchable tariff, becoming in effect January 1, 2005 , provides more flexibility in the operation of wind generation assets and extra values to wind generation assets.

The focus of this paper is to valuate the flexibilities associated with the switching tariff. Physical and market uncertainties associated with wind generation assets, such as wind availability and electricity markets prices, are discussed and modeled. The flexibilities of switching tariff are modeled as compound real options. Numerical techniques are implemented to valuate switching tariff for different wind generation assets, and to identify optimal switching policies and values.

\section{Uncertainties with wind generation assets in electricity markets}

A wind generator faces physical uncertainties such as wind availabilities and market uncertainties such as electricity price movement if participating in electricity markets. The uncertainties expose wind generators to both volumetric and price risk. The dynamics of the physical world, the seasonality of wind, is neither synchronous with the seasonality of demand on electricity, nor the seasonality of prices on electricity. This part models the uncertainties associated with wind generator operation.

The intermittent nature of wind energy is the inherent physical uncertainty associated with wind generation assets. The availability of wind generation can be deducted from the availability of wind and the I/O curve of wind generators. Fig. 1

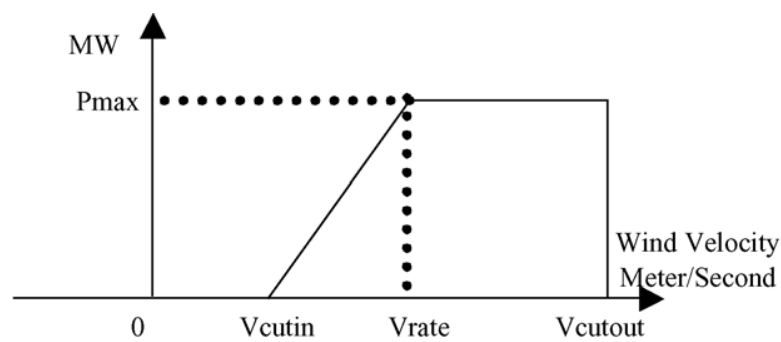

Fig. 1. Active power output as a function of wind velocity (an induction wind generator).

shows an approximated typical I/O curve of a wind generator. Eq. (1) defines parameters used in Fig. 1 and more discussion can be found [5].

Weibull distribution is often used to define the availability of wind. Wind turbine manufacturers often give standard performance figures for their machines using the Rayleigh distribution, which is a special Weibull distribution with shape factor equals to two. The wind generation availability could be derived as a function, the I/O curve of a wind generator, defined on the wind availability.

Wind generation active power generation

$$
\begin{array}{r}
=\left\{\begin{array}{ll}
0 & 0 \leq \text { velocity } \leq V_{\text {cutin }} \\
K_{1}^{*} \text { velocity }+K_{2} & V_{\text {cutin }} \leq \text { velocity } \leq V_{\text {rate }} \\
P_{\max } & V_{\text {rate }} \leq \text { velocity } \leq V_{\text {cutout }} \\
0 & V_{\text {cutout }} \leq \text { velocity }
\end{array}\right\}, \\
K_{1}=\frac{P_{\max }}{V_{\text {rate }}-V_{\text {cutin }}}, K_{2}=-\frac{V_{\text {cutin }}}{V_{\text {rate }}-V_{\text {cutin }}} P_{\max }
\end{array}
$$

The static description with wind generation distribution aggregates the total output of a wind generator over time and contributes to the estimation of total wind energy provided over a given time horizon. The static appropriate is appropriate when a fixed regulated tariff is awarded to a wind generator.

Static approach misses the dynamics of wind generation thus fails to support analysis with time-varying value of electricity. The detailed forecast for wind generation dynamics is accomplished with different approaches [6]. The common approach is to refine the Numerical Weather Prediction (NWP) input with microscale models, historical observations, mesoscale models and statistical modeling. Factors other then wind speed such as wind direction, local air density, local temperature variations, local effects of clouds and rain and so forth are included to provide accurate and location-dependent forecast for wind power generation. This paper assumes that wind speed is the most important single factor and simplifies the impact of other factors using empirical adjustments.

The intermittent nature of wind energy also exposes wind generators to the electricity market architectures and protocols. The US electricity markets impose penalties on Generation Companies (GENCO) if contracted supply obligation is not met. The intermittent nature of wind generation increases risks for wind generators to bid into electricity markets. The current dispatch policy on wind energy at most European countries is to 
dispatch wind energy whenever it is available. After January 2005, the wind generators participating in the Spanish electricity market should present hourly offers with $30 \mathrm{~h}$ in advance, through aggregating agents or by themselves if they do not participate in the market, requiring therefore a wind power forecasting for these $30 \mathrm{~h}$. Wind generators not participating in the market will be penalized if the production deviates more than $20 \%$ from the value offered for each hour. The wind generators participating in the market are obliged to pay the use of secondary energy (used for compensation) if they deviate from their intra-daily offers. This paper focuses more on the switchable tariff and assumes that wind generators could meet their contract obligation on the intra-daily market utilizing short-term forecast.

The time-varying and location-dependent electricity prices are the exogenous market uncertainties associated with wind generation assets. The electricity price movement could be modeled using fundamental or time-series approaches. Fundamental approach such as production cost modeling identifies marginal generation units and binding transmission constraints to generate Location Marginal Price (LMP). The fundamental approach requires tremendous input data including the transmission network, fuel prices, parameters of all generation units and bidding strategies of all market participants. The time-series approach models the prices on electricity as autonomous time series, which could be forecasted by investigating only the historical prices. The time-series approach implicitly assumes weak-form market efficiency and competitive electricity markets. Geometric Brownian Motion (GBM) with mean-reversion and seasonality means is the most used econometrics model as shown in (2). Both of the fundamental and econometric approach could be used to model the movement of prices on electricity. This paper adopts the time-series approach for the Spanish electricity market is a uniform pricing market.

$\mathrm{d}\left(\ln P_{\mathrm{t}}^{\mathrm{E}}\right)=m^{\mathrm{E}}\left(\ln P_{\mathrm{t}}^{\mathrm{E}}-m_{\mathrm{t}}^{\mathrm{E}}\right) \mathrm{d} t+s^{\mathrm{E}} \mathrm{d} W_{\mathrm{t}}^{\mathrm{E}}$

where $m^{\mathrm{E}}$ is the mean-reversion coefficient, $s^{\mathrm{E}}$ the volatility, $m_{\mathrm{t}}^{\mathrm{E}}$ the seasonal pattern and $W_{\mathrm{t}}^{\mathrm{E}}$ is the Weiner Process.

\section{Modeling of switchable tariff as compound real options}

A real option is the right, but not the obligation, to take an action at a predetermined cost called the exercise price, for a predetermined period of time-the life of the option [7]. Real option analysis applies the derivative pricing theory in financial markets to options on real assets. The explicit consideration of the flexibilities of how real assets are operated leads to higher values for assets and different optimal operating decisions [8]. Real option analysis provides GENCOs a new methodology to fully utilize the operating flexibilities, both the flexibilities inherent in the nature of generation assets and provided by exogenous forces [9].

The inherent flexibility with generation assets includes the capability to switching between on and off states, controlling the output level and others. Fossil generation assets could be mod- eled as a set of call option on spark-spread, which is defined as the different between price on electricity and the cost of burning fuel to produce electricity. Wind generator does not use fuel but wind to produce electricity, which leads to very low variable cost. This work assumes that the variable cost of wind generator is always lower than the lowest price on electricity or the fixed regulated tariff, which in turn is consistent with the high priority on dispatching wind energy. The inherent operation flexibility with wind generation assets is modeled as call options on "wind-spread", where windSpread_Regulated is defined as the difference between fixed regulated tariff and the variable cost of a wind generator in

$$
\begin{aligned}
\text { WindSpread_Regulated }= & \text { Fixed_Regulated_Tariff } \\
& - \text { Cost_WindGeneration }
\end{aligned}
$$

and WindSpread_Market is defined as the difference between the electricity price and the variable cost of a wind generator in

WindSpread_Market $=$ Price_Electricity

$$
\text { -Cost_WindGeneration }
$$

The fact that a wind generator is always producing electricity is due to the fact that the wind-spread is assumed to be positive in this work. Whenever a negative wind-spread is expected, a wind generator should take the flexibility to stay offline.

The switchable tariff provides exogenous operation flexibility to a wind generator. This enables a wind generator to choose from either receiving the regulated fixed tariff on its output or receiving the uncertain market prices with extra incentives and prizes. The switching tariff could be modeled as compound real options as shown in Fig. 2.

A compound option is an option whose underlying asset is another option and often be used to hedge or arbitrage on the volatility of volatility associated with the underlying assets [10]. This work use the term "overlying option" to refer to the compound option and the term "underlying option" to refer to the option which can be called or put by the holder of the compound option.

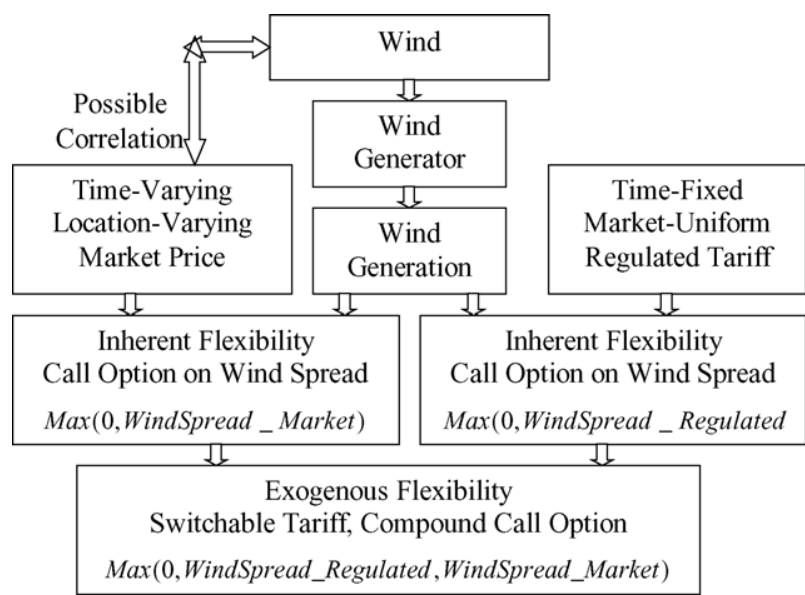

Fig. 2. Switchable tariff modeling with compound option. 


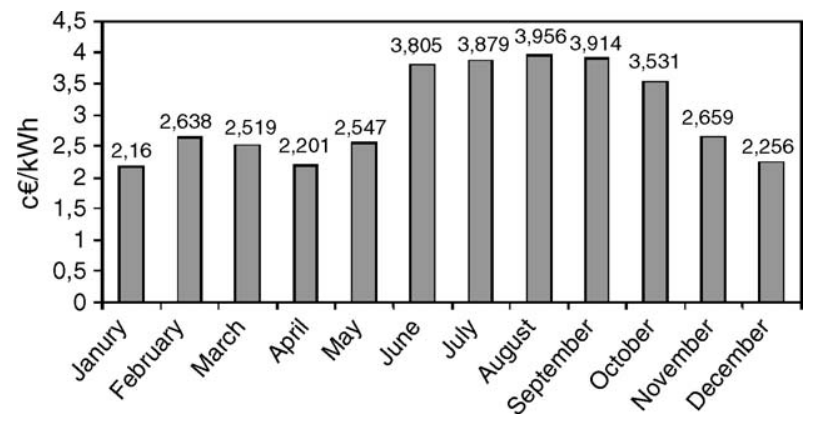

Fig. 3. Spanish electricity market prices movements 2003.

The most intuitive model for the overlying option of switching tariff is a zero-cost option to switch one asset for another, in this work, call options on WindSpread_Regulated and call options on WindSpread_Market. This work models the overlying options of switching tariff as vanilla call options on WindSpread_Market, with the strike price set to WindSpread_Regulated. The vanilla call options approach simplifies the valuations, requires only modeling of the stochastic process of WindSpread_Market. However, the vanilla call options approach requires the WindSpread_Regulated to be a nonnegative constant for the investigated horizon. The underlying options of switching tariff are call options on wind-spreads. The compound option offered by switching tariff could be used to extract more values from the patterns of changes on wind availability and market prices.

The values of wind generation assets, a set of real call options on wind-spreads, are jointly determined by the dynamics of wind generation and electricity price movement. The yearly electricity prices movement in Spanish electricity market is illustrated in Fig. 3, which shows a pattern of peak season from June to October with higher prices than other seasons.

Intermittency of wind power results from diurnal and seasonal wind patterns, driven by daily and seasonal heating and cooling of the earth surface. In the Iberian Peninsula, the diurnal seasonality is such that the wind blows strongly during the beginning of the afternoon and during the night. Wind blows stronger in the winter and in spring. During summer, the wind is usually rather weak. Fig. 4 illustrates the weekly pattern of generation at a wind farm in Spain.

This work models wind speeds to follow fixed patterns, which are estimated from historical data. Wind speeds are modeled to follow fixed yearly pattern with 12 different months. Each month

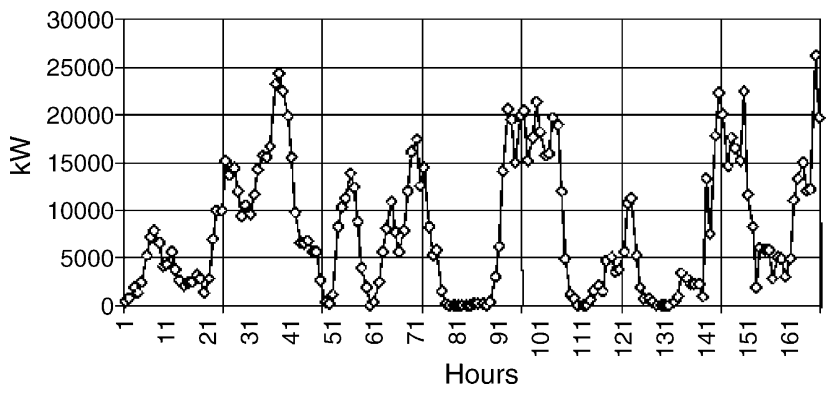

Fig. 4. Weekly production for a wind farm. is modeled to have a typical day, which is in turn defined by hourly wind speed data. The wind speed at a specific hour of the typical day is modeled to follow a distribution. This approach is appropriate for the lack of reliable long-term forecast for wind speeds. The wind generations are calculated from the wind speeds and the I/O curve of the valuated wind generation assets.

This work models electricity market prices to follow stochastic processes, a GBM with mean reversion as shown in (2). The parameters for the GBM such as means, volatilities are estimated from historical data. The virtual prices paths of electricity prices are simulated with assumed GBM model and estimated parameters. This work assumes fixed yearly electricity price pattern. However, the electricity market prices vary depending on fundamental economic drivers such as fuel prices, hydrological conditions and demand growth among others. The fundamental economic drivers enter into the GBM models, if included, by varying the electricity prices means of GBM.

The stochastic processes of wind speeds and market prices could be correlated when there is a significant penetration of wind energy on an existing electricity market or a strong connection between the availability of wind with electricity demand. It is found that there is a tendency that more wind power in an electricity market in the short run leads to relatively lower spot prices, while less wind power implies relatively higher spot prices [11]. For the LMP framework, it is expected that the wind generation and LMP at a specific bus are correlated. For the uniform electricity pricing framework, the correlation between market price and aggregated wind generation depends on factors such as wind penetration and others. For a specific wind generation asset within a specific electricity market, the intercorrelation between the wind generation and electricity price movement should be examined.

This work aims to valuate yearly and monthly switching tariff as compound real options. When the tariff can only be switched monthly/yearly, the underlying options of switching tariff could be modeled as Asian call option on wind-spread. The payoffs of the underlying Asian call options depend on the monthly averaged WindSpread_Market, which is averaged monthly using wind generation as weights as shown in

$$
\begin{aligned}
& \text { WindSpread_Market } \text { month } \\
& =\frac{\sum_{\text {Hourly }} \text { WindSpread_Market }_{\text {hour }} \times \text { Wind_Generation }_{\text {hour }}}{\sum_{\text {Hourly }} \text { Wind_Generation }_{\text {hour }}}
\end{aligned}
$$

The valuation of switching tariff begins with modeling of the stochastic processes of WindSpread_Market, especially the yearly and monthly patterns. This work implements Monte Carlo simulation to generate virtual hourly WindSpread_Market from detailed models of wind generation and electricity prices discussed above. The hourly WindSpread_Market is then averaged as shown in (5). Different average time span could also be implemented if the corresponding switching tariff is valuated. The Monte Carlo simulation provides a general and robust solution to the valuation of switching tariff for the underlying WindSpread_Market does not follow normal or lognormal 
distributions. The robust of Monte Carlo simulation contributes to handle the interdependency between the dynamics of wind generation and electricity prices.

\section{Numerical examples}

This section formulates two switching tariff scenarios, which are solved numerically. Under each scenario, two identical wind generators are valuated and compared. The first scenario strictly follows the yearly switch of tariff as stated in Real Decreto $436 / 2004$. This scenario aims to illustrate the impact of switchable tariff on the values of wind generation assets, and identify which month is the optimal time for switching.

The second scenario assumes that a wind generator could switch its tariff each month provided the switch decision is made one-month ahead. With a higher switching frequency, this scenario aims to illustrate that more efficiency could be gained by allowing higher switching frequency. It also aims to show that higher switching frequency reduces the operation risk of wind generators for more flexibility on switching are provided.

It is assumed that two GE1.5SE wind generators are to be installed at Barcelona and Valencia in Spain, and Table 1 illustrates the parameters for the wind generators [12].

This work estimates the fixed wind patterns with historical data gathered from 1972 to 1982 [13]. Table 2 gives the wind patterns at Barcelona and Valencia weather stations, measured, respectively, at height at $6 \mathrm{~m}$ and $20 \mathrm{~m}$ from the ground.

The logarithm wind speed profile is assumed to be valid for height of the investigated wind generators. The wind speeds at the height of wind turbines $65 \mathrm{~m}$ are adjusted as shown in (6). The yearly average wind speeds at Barcelona and Valencia equal to $5.0 \mathrm{~m} / \mathrm{s}$ and $5.1 \mathrm{~m} / \mathrm{s}$, which is not quite suitable for the GE1.5SE wind generator. This work assumes that the wind speeds measured at the weather station are $50 \%$ for wind speeds at the corresponding wind farms.

$u(z)=\frac{u^{*}}{k} \ln \frac{z}{z_{0}} \Rightarrow u\left(z_{1}\right)=\frac{\ln \left(\frac{z_{1}}{z_{0}}\right)}{\ln \left(\frac{z_{2}}{z_{0}}\right)} \times u\left(z_{2}\right)=C \times u\left(z_{2}\right)$

where $u(z)$ is the wind speed at height $z, z_{0}$ the surface roughness length, $k$ the Von Karman constant, $u^{*}$ the friction velocity and Barcelona_C: 2.3360 and Valencia_C: 1.3940.

The missing hourly wind speeds are estimated by interpolating the existing data. This work assumes roughness class one, defined as a terrain as open area with few windbreaks surface roughness length $\left(z_{0}\right)=0.03 \mathrm{~m}$, for both wind generators at Barcelona and Valencia. The hourly wind speeds are assumed

Table 1

GE1.5SE wind generator parameters

\begin{tabular}{lc}
\hline Tower height $(\mathrm{m})$ & 65 \\
Cut-in wind speed (m/s) & 4 \\
Rated wind speed (m/s) & 13 \\
Cut-out wind speed (m/s) & 25 \\
Rated capacity (MW) & 1.5 \\
\hline
\end{tabular}

Table 2

Hourly wind speed for a typical year (m/s)

\begin{tabular}{|c|c|c|c|c|c|c|c|c|c|}
\hline \multirow[t]{2}{*}{ Month } & \multicolumn{8}{|c|}{ Hour } & \multirow[t]{2}{*}{ Average } \\
\hline & 0 & 3 & 6 & 9 & 12 & 15 & 18 & 21 & \\
\hline \multicolumn{10}{|l|}{ Barcelona } \\
\hline January & 2.8 & 3.4 & 3.6 & 4.3 & 3.9 & 3.7 & 2.1 & 2.2 & 3.3 \\
\hline February & 2.0 & 2.8 & 3.2 & 4.1 & 4.0 & 4.8 & 2.6 & 1.8 & 3.2 \\
\hline March & 1.7 & 2.1 & 2.8 & 4.0 & 4.8 & 5.3 & 4.0 & 2.0 & 3.4 \\
\hline April & 1.5 & 1.8 & 2.6 & 3.5 & 5.2 & 5.3 & 4.0 & 1.8 & 3.2 \\
\hline May & 1.1 & 1.3 & 2.0 & 3.3 & 5.1 & 5.1 & 3.8 & 1.7 & 3.0 \\
\hline June & 0.8 & 1.2 & 2.0 & 3.3 & 5.1 & 5.4 & 4.1 & 1.6 & 3.0 \\
\hline July & 0.8 & 1.0 & 2.0 & 3.1 & 5.3 & 5.4 & 4.1 & 1.4 & 2.9 \\
\hline August & 1.0 & 1.3 & 2.2 & 2.9 & 4.9 & 5.1 & 3.6 & 1.4 & 2.8 \\
\hline September & 1.4 & 1.6 & 2.5 & 3.1 & 4.5 & 4.9 & 2.9 & 1.2 & 2.8 \\
\hline October & 1.7 & 2.5 & 3.2 & 4.1 & 3.8 & 4.3 & 2.1 & 1.5 & 2.9 \\
\hline November & 2.5 & 3.2 & 3.5 & 4.2 & 3.5 & 3.4 & 1.9 & 1.8 & 3.0 \\
\hline December & 3.3 & 3.8 & 3.9 & 4.3 & 4.1 & 3.7 & 2.3 & 2.6 & 3.5 \\
\hline Average & 1.7 & 2.2 & 2.8 & 3.7 & 4.5 & 4.7 & 3.1 & 1.8 & NA \\
\hline \multicolumn{10}{|l|}{ Valencia } \\
\hline January & 3.2 & 3.3 & 3.2 & 3.7 & 4.4 & 5.6 & 3.6 & 3.0 & 3.8 \\
\hline February & 3.3 & 3.3 & 3.3 & 4.2 & 5.1 & 6.3 & 4.4 & 3.1 & 4.1 \\
\hline March & 2.5 & 3.0 & 2.7 & 4.0 & 5.4 & 6.8 & 4.8 & 2.5 & 4.0 \\
\hline April & 2.1 & 2.2 & 2.1 & 3.5 & 5.6 & 6.5 & 4.8 & 2.1 & 3.6 \\
\hline May & 1.4 & 1.4 & 1.5 & 3.0 & 5.6 & 6.3 & 4.5 & 1.6 & 3.2 \\
\hline June & 1.0 & 1.2 & 1.2 & 2.2 & 5.4 & 6.1 & 4.9 & 1.5 & 2.9 \\
\hline July & 0.9 & 0.8 & 1.3 & 1.7 & 5.2 & 6.2 & 4.8 & 1.6 & 2.8 \\
\hline August & 1.1 & 1.0 & 1.0 & 1.6 & 4.9 & 5.9 & 4.6 & 1.3 & 2.7 \\
\hline September & 1.4 & 1.2 & 1.3 & 1.9 & 4.1 & 5.6 & 3.8 & 1.3 & 2.6 \\
\hline October & 2.1 & 2.4 & 2.5 & 3.5 & 4.4 & 5.8 & 3.2 & 2.3 & 3.3 \\
\hline November & 2.5 & 2.6 & 2.7 & 3.3 & 3.5 & 5.2 & 2.4 & 2.4 & 3.1 \\
\hline December & 3.7 & 3.6 & 3.7 & 4.1 & 4.7 & 5.8 & 3.4 & 3.4 & 4.1 \\
\hline Average & 2.1 & 2.1 & 2.2 & 3.0 & 4.8 & 6.0 & 4.1 & 2.2 & NA \\
\hline
\end{tabular}

to follow Weibull distributions. At the desired height of $65 \mathrm{~m}$, roughness class one, Barcelona has Weibull distributions with shape factor as 1.79 and Valencia has Weibull distributions with shape factor as 1.31 [13]. The hourly wind generations are calculated based on the wind generator parameters shown in Table 1.

Operador del Mercado Ibérico de Energía (OMEL) operates the Spanish electricity market including daily and intra-day market. The daily market on electric energy accounts for up to $70-78 \%$ of all the transactions during 1998-2002 on Spanish market [14]. This work estimates the parameters for Geometric Brownian Motions based on the Spanish daily electricity market historical data [15].

The simulated WindSpread_Market at Barcelona for January 2004 has a mean at $€ 267$ (kW month $)^{-1}$ with standard deviation at $€ 23.94$ (kW month) ${ }^{-1}$, as shown in Fig. 5.

The yearly and monthly switching tariffs as vanilla call options on WindSpread_Market, with WindSpread_Regulated as strike prices are valuated also by the Monte Carlo simulation. The same wind generation assets at different locations are valuated under regulated fixed tariff, electricity markets price taking, yearly switching tariff and monthly switching tariff. The payment to a wind generator comes from multiple resources including daily markets, capacity payments and others. This work focuses on the revenue from selling electric energy to daily market, and assumes the fixed tariff for selling into daily market 
Table 3

Values and risks of wind generation assets at different locations under different renumeration frameworks

\begin{tabular}{|c|c|c|c|c|}
\hline & Fixed tariff & Market prices & Yearly switching tariff & Monthly switching tariff \\
\hline \multicolumn{5}{|c|}{ Values (€/(kW year)) } \\
\hline Barcelona & 3804.3 & 3595.2 & 3804.3 & 4049.1 \\
\hline Valencia & 4991.4 & 4644.3 & 4991.4 & 5288.4 \\
\hline \multicolumn{5}{|l|}{ Variances $(\%)$} \\
\hline Barcelona & 111.57 & 106.54 & 111.57 & 118.08 \\
\hline Valencia & 379.2 & 366.01 & 379.2 & 406.53 \\
\hline
\end{tabular}

as the yearly mean for electricity prices. The simulation results are given in Table 3 .

Assume the regulator could perfectly estimate the yearly averaged price, a market price taker in fact takes more risk in its operation and may suffer opportunity loss. This explains why some wind generators hesitate to participate the electricity markets.

The fixed yearly pattern is the underlying reason why yearly switchable tariff has the same results with the fixed tariff, which is better than market price taking. If the assumption of fixed yearly pattern for electricity prices were relaxed, then the yearly switchable tariff would be of more values. Information on fundamental economic drivers such as the hydrological forecast, demand growth on electric energy and volatile fuel prices would play an important role in the optimal switching. The switching of wind generators not only will achieve more efficiency, but also will facilitate the exchange of information.

It is also shown that the monthly switching tariff is of more value, which extracts the most values from operating wind generation assets. The monthly switchable tariff is also expected to further reduce the operation risk of wind generation assets if forecasts on the patterns of electricity prices and wind are modeled. The one-month ahead forecast would provide more valuable information for a wind generator to actively manage its wind generation assets. This example includes very limited operating flexibilities by assuming wind generators have no forecasting power.

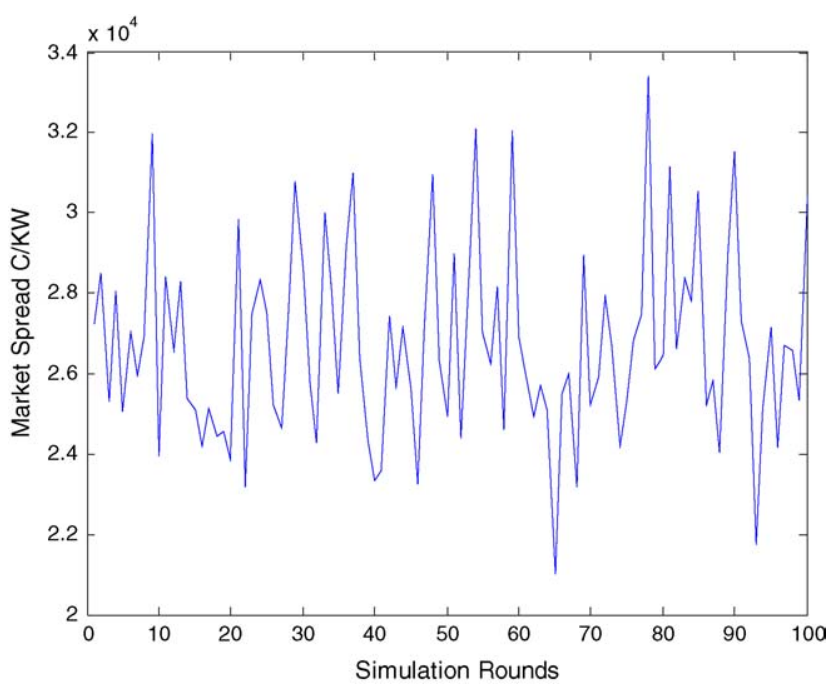

Fig. 5. Market spread in January 2004

\section{Conclusion}

This work applies real option analysis to valuate the switchable tariff for wind generators in Spanish electricity markets. Identical wind generation assets are valuated to investigate the impacts of switchable tariff. It is shown that both the values and operation risk of wind generation assets are changed by the switchable tariff. The fixed tariff gives higher priority to the quantity of wind generation, namely the total wind energy exacted. The time-varying and location-dependent market electricity prices differentiate wind energy and gives higher priority to the quality of wind generation, namely the market value created. The switching tariff provides means to appropriately compensate wind generators, and balance the quantity and quality of wind energy. It is also shown that switching tariff reduces the risk exposures of wind generators. A monthly switching tariff is proposed and compared to the existing yearly switching tariff. It is shown that monthly switching tariff is of more value to wind generators for its great flexibilities and accuracy of short-term forecasts.

\section{References}

[1] European Union Council, Directive 2001/77/EC of the European Parliament and of the Council of 27 September 2001 on the Promotion of Electricity Produced From Renewable Energy Sources in the Internal Electricity Market.

[2] American Wind Energy Association, Wind Power Outlook 2004, http://www.awea.org/pubs/documents/Outlook2004.pdf (retrieved March 13, 2004).

[3] Y. Makarov, D. Hawkins, E. Leuze, J. Vidov, California ISO Wind Generation Forecasting Service Design and Experience, http://www.caiso. com/docs/2002/06/12/2002061211030528205.pdf (retrieved).

[4] Red Eléctrica DeEspaña, Real Decreto 436/2004. Metodología para la actualización y sistematización del régimen jurídico y económico de la actividad de producción de energía eléctrica en régimen especial, http://www.ree.es/cap03/pdf/simel/RD436_2004.pdf (retrieved October 14, 2004).

[5] L. Landberg, G. Giebel, H.A. Nielsen, T.S. Nielsen, H. Madsen, Shortterm prediction-an overview, Wind Energy 6 (2003) 273-280.

[6] T. Burton, D. Sharpe, N. Jenkins, E. Bossanyi, Wind Energy Handbook, John Wiley \& Sons, 2001.

[7] T. Copeland, V. Antikarov, Real Options: A Practitioner's Guide, Texere, 2001.

[8] A. Dixit, R. Pindyck, Investment Under Uncertainty, Princeton University Press, Princeton, NJ, 1994.

[9] W. Yu, G.B. Sheble, Applying Real Option to the Operation of Generation Assets: A Fuzzy Approach, Bologna Power Tech, 2002.

[10] J.C. Hull, Options, Futures, and Other Derivatives, Prentice Hall, 2002.

[11] P.E. Morthorst, Wind power and the conditions at a liberalized power market, Wind Energy 6 (July/September (3)) (2003) 297-308. 
[12] GE Wind Generator Fact Sheet, http://www.gepower.com/prod_serv/ products/wind_turbines/en/downloads/ge_15_brochure.pdf (retrieved October 12, 2004).

[13] I. Troen, E.L. Petersen, European Wind Atlas, Ris〉 National Laboratory, Roskilde, Denmark, 1989.

[14] Operador del Mercado Ibérico de Energía, Spanish Electricity Market Annual Report, 2002, http://www.omel.es/frames/en/resultados/ resultados.htm (retrieved July 2003).

[15] Operador del Mercado Ibérico de Energía, Spainish Electricity Markets Results, http://www.omel.es/frames/en/resultados/resultados.htm (retrieved March 13, 2004).

Wang $Y u$ is a Ph.D. candidate of electrical engineering at Iowa State University. He attended Shanghai Jiaotong University, receiving B.S.E.E. (1995). He received his M.S.E.E. in 2000 from Nanjing Automation Research Institute. Mr. Yu received his M.S. in economics at Iowa State University 2004, specializing in economics and finance of deregulation. His research interests include electricity market modeling and analysis, generation assets operation and risk management, power system optimization and control.

Gerald B. Sheblé is a professor of electrical engineering at Iowa State University since 1995 . He attended Purdue University, receiving B.S.E.E. (1971) and M.S.E.E. (1974). He received his Ph.D. in 1985 from Virginia Tech. In 2001, Dr. Sheblé received his M.B.A. from the University of Iowa, specializing in economics and finance. His research interests include power system optimization, scheduling and control, artificial neural networks, genetic algorithms, genetic programming and optimization and control technologies for various industrial applications.

Joao A. Peças Lopes is an associate professor with Aggregation in the Department of EE of the Faculty of Engineering of University of Porto. He obtained an EE degree (five years course) in 1981 from University of Porto and a Ph.D. degree also in EE from the same university in 1988 . In 1996, he got an Aggregation degree. In 1989, he joined the staff of INESC as a senior researcher and he is presently co-coordinator of the Power Systems Unit of INESC Porto and a senior member of the IEEE. Dr. Peças Lopes has been leading several research and consultancy projects related with the integration of renewable generation and DG in the power system.

Manuel António Matos was born in 1955 in Porto (Portugal). He is presently full professor at the Faculty of Engineering of the University of Porto, Portugal, and the manager of the Power Systems Unit of INESC Porto. He also collaborates with the Management School of the University of Porto. 